\title{
Motivation nutzen
}

_ Mit Sicherheit haben Sie das bei der Therapie so oder so ähnlich auch schon erlebt: Sie wenden eine ähnliche Behandlung bei Klienten mit vergleichbaren Symptomen an. Bei dem einen stellen sich viel schneller Fortschritte ein, während der andere kaum Erfolge hat und die Behandlung stagniert. Eine Erklärung dafür könnte die Motivation sein.

_ Auch von sich selbst weiß man, wie extrem wichtig die eigene Motivation ist. Hat man keine Lust auf etwas, wird man es nur halb so gut erledigen. Macht man etwas gerne, klappt es doppelt so schnell. Offerieren wir unseren Klienten motivierende Therapieangebote, sind wir erfolgreicher. Wenn wir etwas suchen, das ihrem Lebenskontext nahekommt. Etwas, das ihren Alltag ausmacht. Für den einen kann das Kuchen backen sein (॰ Seite 22), für den anderen ein Besuch auf dem Oktoberfest (๑ Seite 32).

_Auch bei der Compliance von Kindern nimmt die Motivation einen hohen Stellenwert ein. Kinder mit ADHS, die mit leuchtenden Augen klettern, halten sich womöglich leichter an vorgegebene Regeln und Strukturen. Die Ergotherapeuten können damit deren Bewegungsdrang gezielt für die Behandlung nutzen (॰ Seite 18).

_ Von einer Sache bin ich fest überzeugt: Je motivierter die Klienten bei der Therapie sind, desto schneller stellen sich Erfolge ein. Wenn sie zufrieden sind und Fortschritte machen, kommen sie gerne wieder. Und nicht zuletzt wird man auch mit sich selbst und seiner Arbeit zufriedener sein.

Einen frühlingshaften Motivationsschub wünscht Ihnen

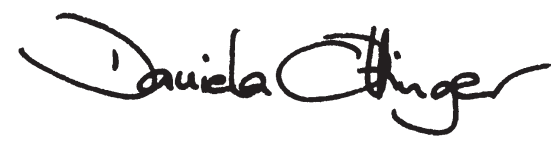

\section{ZU GEWINNEN \\ Kursplatz oder Goniometer}

Diesmal verlosen wir den Einführungskurs „Entwicklungs- und Lerntherapie nach PäPKi®i " bei den Diakonischen Diensten Hannover vom 11. bis 12.9.2009. Außerdem gibt's ein Goniometer zu gewinnen.

Schicken Sie einfach bis zum 30. April eine Postkarte mit dem jeweiligen Stichwort an die Redaktion. Viel Glück! 